\title{
INTEGRATION OF ENGINEERING DESIGN AND COMMUNICATION IN A FIRST YEAR COURSE P. Wild ${ }^{1}$, Y. Coady ${ }^{1}$, M. McGuire ${ }^{1}$, G. Van Gyn ${ }^{2}$, S. Last ${ }^{3}$
}

1. Faculty of Engineering; 2. Exercise Science, Physical \& Health Education; 3. Department of English, University of Victoria pwild@uvic.ca, ycoady@uvic.ca, mmcguire@ece.uvic.ca, gvangyn@uvic.ca, sulast@uvic.ca

\section{INTRODUCTION}

ENGR 110 - Design and Communications is a new one-term course in the first year engineering program at the University of Victoria in which engineering design and communication learning outcomes are developed in an integrated manner. Two key objectives of this course are: (1) to enhance student engagement in the first year program by establishing connections between their academic activities and engineering design as it is practiced by professional engineers in industry and (2) to enhance student understanding of the critical role that communication plays in engineering professional practice.

Courses that integrate engineering design with technical communication instruction and activities have been implemented at other institutions [1,2]. However, this is the first "writing in the discipline" course that fulfills the Undergraduate English Requirement at UVic.

\section{METHODS}

In each week of the term, instructor-student contact is comprised of a one-hour plenary lecture, three one-hour seminars, a one-hour tutorial, and a two-hour design laboratory. In the plenary lecture, course instructors and guest speakers, drawn primarily from industry, introduce fundamental principles of engineering design in the context of projects taken from their professional practice. These fundamental principles include: engineering design process; teamwork; new product/process/system design; environmental factors; human factors; business context; regulatory issues; as well as creative and critical thinking.

Speakers also identify and discuss the essential role of communications and its contribution to the successful completion of specific projects in their professional engineering practice. At least one of the plenary speakers addresses the importance of communication in engineering design and in engineering professional practice in general. This individual will speak, in particular, to the importance of communication skills to the success of his/her engineering career. Speakers will also be sought out who are able to describe instances where poor communication led to design failures.

In the seminars, students develop university-level writing and research skills through assignments that are based on engineering design topics that link to the design-based activities of the plenary lecture, tutorial and design laboratory. Students are introduced to the basics of academic reading, researching, and writing in the context of the discipline of Engineering. Students read a variety of academic articles on engineering and on writing topics; they identify academic conventions, rhetorical strategies, structures and patterns, examine them critically, and apply them to their own writing. Students use the writing process to plan, draft and revise a variety of typical academic writing assignments that ask them to summarize, analyze and synthesize ideas and forms of academic writing. Students actively reflect on their learning during writing assignments on the process of design and composition.

In the design laboratory, students work in teams of three to complete a number of design exercises and one major design project. Parts of the design exercises and the entire design project are completed using the VEX Robotic Kits (Innovation First International, Inc., Greenville, TX). These kits are comprised of structural components, power transmission components, electric motors, sensors and a microcontroller. The microcontroller is programmed using ROBOTC, a version of $\mathrm{C}$ developed for the VEX microcontroller. These exercises and projects reinforce the fundamental principles of engineering design that are introduced in the plenary lecture series.

In the tutorial, students receive instruction in software, mechanical and electrical engineering topics that are needed to undertake the project.

As an overarching theme, similarities between good writing process and good design process are also discussed. Both processes require clear understanding of purpose, background research, planning and editing/revision.

In ENGR 110, the subject of the major design project acts as a central theme for the course. Selected speakers in the plenary lecture series address this central theme. For example, in the Spring 2010 offering, the objective of the major design project was to design, build and test a scale model of a moving-span bridge to replace the Johnson Street Bridge in Victoria. This topic was selected (1) because there is significant controversy surrounding the decision to replace or renew the existing structure and (2) because a moving-span bridge incorporates elements of all of the engineering disciplines at UVic (i.e. Mechanical, Electrical, Computer and Software Engineering). Speakers relevant to this topic included engineers from the City of Victoria who are involved in the bridge replacement/refurbishing project and a Professor of Civil Engineering who has extensive experience in professional practice as a bridge designer.

Selected readings, research and writing assignments focused on this central theme. For example, a number of the readings for the spring offering of ENGR 110 dealt with technical, financial and aesthetic aspects of bridge design. Students were encouraged to use these articles or bridge design related plenary presentations as the subject of their written assignments (i.e,. descriptive writing assignment, summary assignment, short comparison assignment, annotated bibliography assignment, comparative rhetorical analysis essay and research essay).

Students were also directed to select topics for reading, research and writing assignments that are relevant to the design of other (i.e. nonbridge) engineering artefacts or to engineering design, in general. Articles were made available, in the coursepack or on the course website. Students were also encouraged to find their own topics/materials.

\section{RESULTS AND DISCUSSION}

This course was first offered in the January-April term, 2010. Results of a midterm survey of students followed by focus group data suggest that the course was achieving the objective of enhanced engagement in the first year of engineering and enhanced understanding of the role of communications in the engineering profession. The discussions in focus groups conducted towards the end of the course also give more specific direction for improving the efficacy of this integrated course.

Not surprisingly, this midterm feedback indicates that students are more comfortable with traditional presentation formats and methods over those used in this course that focus on "soft skills". That is, prescribed hands-on activities were perceived as being more valuable than plenary speakers, and traditional prescriptive quantitative evaluation procedures were vastly preferred over more open-ended design rubrics. These results underscore the critical disconnects that exist between current expectations nurtured in traditional academic settings, versus professional realities for practicing engineers.

It is important to note however, that our results also indicate a significant appreciation of an early exposure to professional practices. Our intent is to better leverage this aspect of the course to help students develop a more holistic appreciation of the skill sets involved in their disciple. For example, even de-stigmatizing the terminology by referring to "higherorder skills" as opposed to "soft skills", and using Meyers-Briggs to establish group membership rather than random assignment, could better align with the priorities and expectations these students bring into the course.

A secondary benefit of the plenary lectures is that the students were exposed to several different fields of engineering such as biomedical engineering, environmental engineering, aerospace engineering, and assistive technologies. Anecdotal evidence indicates that the students found this variety useful in motivating them to continue their engineering education.

\section{REFERENCES}

1. Barchilon $\mathrm{MG}$, Integrating engineering design and engineering communication to enhance quality, Proceedings-Frontiers in Education, 1996, pp 11-12.

2. Lengsfeld CS, Edelstein G, Black J, Hightower N, Root M, Stevens K, Whitt M., Engineering concepts and communication: A two-quarter course sequence Journal of Engineering Education, 93-1, 2004, pp. 79-85. 